\title{
Realistic mathematics education: Mathematical reasoning and communication skills in rural contexts
}

\author{
Anderson Leonardo Palinussa, Juliana Selvina Molle, Magy Gaspersz \\ Mathematics Education Study Program, Faculty of Teacher Training and Education, Pattimura University, Indonesia
}

\begin{tabular}{|c|c|}
\hline Article Info & ABSTRACT \\
\hline Article history: & \multirow{9}{*}{$\begin{array}{l}\text { Mathematics learning has always been a problem in the world of education in } \\
\text { Indonesia especially in the Province of Maluku, which is a thousand island } \\
\text { area. The geographical position of Maluku, which is an area of the archipelago, } \\
\text { is quite extensive, affecting the quality of students in mathematics. One } \\
\text { approach that is recommended to overcome mathematical problems of rural } \\
\text { island-based students is realistic mathematics education (RME). The purpose } \\
\text { of this study was to analyze the effect of RME on mathematical reasoning and } \\
\text { communication skills in a rural context. The research design used was quasi } \\
\text { experiment. The sample size was } 130 \text { students from several junior high schools } \\
\text { in Central Maluku Regency. The instrument developed was in the form of } \\
\text { problem descriptions to measure students mathematical reasoning and } \\
\text { communication skills. The findings prove that RME has a significant influence } \\
\text { on students' mathematical reasoning and communication skills. Thus, RME } \\
\text { can be recommended in improving students' mathematical reasoning and } \\
\text { communication skills in the island-based rural context. }\end{array}$} \\
\hline Received Oct 3, 2020 & \\
\hline Revised Mar 9, 2021 & \\
\hline Accepted Apr 11, 2021 & \\
\hline Keywords: & \\
\hline Culture & \\
\hline Mathematical communication & \\
\hline Reasoning skill & \\
\hline Rural context & \\
\hline
\end{tabular}

This is an open access article under the CC BY-SA license.

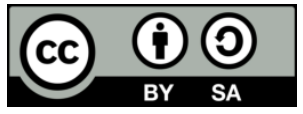

\author{
Corresponding Author: \\ Anderson Leonardo Palinussa \\ Mathematics Education Study Program, Faculty of Teacher Training and Education \\ Pattimura University \\ Jln. Ir M. Putuhena, Campus Poka, Ambon, Indonesia \\ Email: palinussaandersonl@gmail.com
}

\section{INTRODUCTION}

The importance of education for every child of the nation causes equal distribution of education that must be done. However, a gap causes implications for the quality of education. The eastern region has always been the focus, especially Maluku, which is a province of a thousand islands with education quality that is still far from expectations when compared to other regions in Indonesia [1]. Quality mathematics learning is more dominant for students in urban areas compared to students in rural areas [2]. Surveys in developed countries like the United States show that the three main challenges that cause low quality education in rural areas are low teacher salaries, social isolation and geographic isolation [3].

The main challenge also makes the problem of difficulty in learning mathematics, so that it has an impact on students' mathematical reasoning skills [4]. Mathematical reasoning is more directed at the attitude to think systematically, logically and produce a new conclusion based on facts and more relevant sources [5]. Students more easily understand mathematics when their reasoning skills are good and able to communicate mathematically so that mathematical symbols will be more meaningful [6]. Scientific reasoning and mathematical communication skills have a very close relationship. Communication skills are an important aspect so that students have the skill to solve mathematical problems, especially mathematical solutions related to students' real life [7], [8]. The results of studies in several countries including Turkey prove that the scientific reasoning of students for grade 8 students is still very low [9]. Besides that, in the USA the same thing shows 
that scientific reasoning of students is still low so that it disrupts the learning process of STEM [10]. The results of other studies about communication skills for students in Indonesia are also still low in terms of IMO and PISA [11].

One of the recommended learning models is realistic mathematics learning (RME) since it utilizes real-world situations for students to construct their understanding and knowledge. RME is based on the ideas of Hans Freudenthal in the 1970s with his friends at the Freudenthal Institute [12]. Experts see mathematics as one of the transmissions of knowledge [13]. RME develops in the Netherlands for elementary school students, but it progresses to junior high school level and is known as the Indonesian Realistic Mathematics Education (PMRI) in Indonesia [14]. RME views mathematics as a human activity, not as mere knowledge ready to use [15]. It utilizes the surrounding environment to bring thoughts and provide the broadest opportunities for students in understanding mathematical material.

Providing the broadest opportunities for students to learn mathematics in a real-world context is very important to provide a solid foundation on a mathematical topic [16]. The relevant topic is geometry, especially in the form of a flat structure using students' daily lives, especially for students in rural areas that are limited by facilities. By utilizing the existing daily context, the brain's ability to understand a problem in mathematics will be formed and communication between students will be built properly without any restrictions [17]. Appropriate learning tools will bring students into their natural thinking or playing environment [18], [19]. Learning tools can help teachers to make classrooms as a place to learn and solve mathematical [20], [21].

RME is a learning approach that is considered appropriate in developing mathematics in a rural context [12]. RME experts explain that learning mathematics must be linked to reality [22], [23]. This means that mathematics must be close to the child and relevant to the child's daily situation, especially student life. One material that is considered relevant is geometry material in junior high school students. The research report informs us that the learning outcomes of students in Kendari, on geometry material are still low [24]. In addition, the mathematics learning outcomes of vocational students in the Netherlands are still low, where students still have difficulty solving mathematical problems [25].

One of mathematics learning that is in accordance with the rural context is RME [26]. Until now, there has been a lack of attention from the government in Maluku, especially schools in rural areas [27]. Rural schools tend to be smaller and facilities are inadequate in terms of teaching staff and infrastructure [28]. Therefore, this research was more focused on schools and students in rural areas that are lacking in terms of teaching staff and facilities by prioritizing everyday contexts such as the learning environment and the playing environment. Based on the existing problems, this study aimed to analyze the effect of RME on mathematical reasoning and communication skills in a rural context.

\section{RESEARCH METHOD}

\subsection{Research design}

This study used a quasi-experimental design with the design of three pre-test -post-test control classes and three experimental classes from three different schools that were used as research samples. The grouping of students was determined based on the level of the school according to the results of accreditation from schools with accreditation criteria type A, B, C, and categories of levels of mathematical skills with learning using the RME approach in the rural context and conventional learning.

\subsection{Population and research sample}

The study was conducted in Central Maluku Regency, Indonesia on several junior high schools including Public Junior High School 1 Masohi with accreditation A, Public Junior High School 1 Amahai with accreditation B and Christian Junior High School of Masohi with accreditation C. The sample size was 130 students at grade VII. Division of students based on the level of knowledge, among others, low, medium and high.

\subsection{Research instruments}

The instruments were essay tests consisting of five mathematical reasoning questions and communication skills tests. Previously, the five questions have been validated by experts so that they meet the criteria properly and can be used. In addition, validation was carried out on a number of junior high school mathematics teachers in Masohi Regency who were familiar with and understand the mathematics needs of students. Before conducting student learning interventions, a pre-test was conducted to test students' mathematical abilities. The pre-test questions consist of five questions which are similar to the post-test questions. The details of the categories of students' mathematics learning outcomes are presented in Table 1. One example of a test instrument developed as shown in Figure 1, "If you look at the roof of the house on the side, it looks like an equilateral triangle. If the side length is $2 x+4 \mathrm{~cm}$ and the circumference is $150 \mathrm{~cm}$, 
determine the value of $\mathrm{x}$ ". The early mathematical skills test, the criteria for grouping are based on students' mathematical skills scores based on benchmark reference assessments as shown in Table 1.

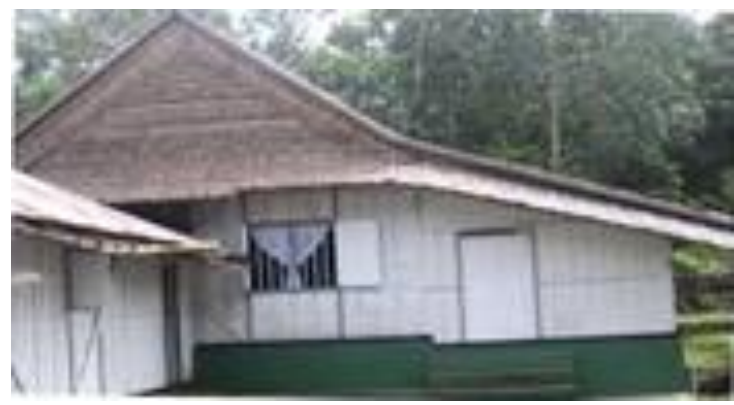

Figure 1. Test instrument developed

Table 1. Criteria for early mathematical students skill (EMSS) categories

\begin{tabular}{lc}
\hline Early mathematical student skills (EMS) & Category \\
\hline EMSS $\geq 75 \%$ ideal score $=75$ & High \\
$55 \%$ ideal score $=55<$ EMSS $<75 \%$ ideal score $=74$ & Medium \\
EMSS $\leq 55 \%$ ideal score $=54$ & Low \\
\hline
\end{tabular}

\subsection{Data collection technique}

Data collection techniques were interview guidelines, questionnaires and documentation. Interview guidelines were in the form of questions compiled systematically in the form of questions of mathematical reasoning and communication skills to re-check the difficulties of students in solving problems. The questionnaire instrument was in the form of student and teacher responses to the learning carried out and the provision of solutions for future learning development. The results of the documentation were in the form of students' answers during the pre-test, process and post-test until the activity during the process of collecting learning outcomes data.

\subsection{Data analysis technique}

Data analyzed in this study were obtained from tests of students' mathematical reasoning and communication skills. The test was done at the beginning of learning and at the end of learning. Based on the pre-test and post-test scores of the two skills, the N-Gain Score was calculated and processed according to the problem and the proposed hypothesis.

Data processing in this research was carried out as: 1) Prerequisite test; 2) If the data were normal, the T-test was used to test the difference of two averages and the Anova test to test the difference of more than two averages; 3) If the data were known to be not normally distributed, non-parametric statistical rules used Wilcoyon test or Mann-Whitney test to test the difference of two samples and Krurskal walls test to test the difference of more than two lines.

In addition to quantitative analysis, a qualitative analysis of the answers to each item was carried out, observational data, interview data, and student response data. It aimed to examine further about mathematical reasoning and communication skills, and to find out whether the implementation of learning in accordance with the provisions of learning set in both learning.

\section{RESULTS AND DISCUSSION}

Quantitative data obtained from the results of tests of mathematical skill and mathematical reasoning skill tests. The distribution of the research sample is presented in Table 2.

Table 2. Distribution of research samples

\begin{tabular}{ccccccccc}
\hline Early mathematical & \multicolumn{3}{c}{ Experimental group (RME) } & \multicolumn{3}{c}{ Control class (Conventional) } \\
student skills & High & Medium & Low & Total & High & Medium & Low & Total \\
\hline Low & 7 & 2 & 10 & 19 & 12 & 6 & 10 & 28 \\
Medium & 10 & 9 & 10 & 29 & 10 & 9 & 9 & 28 \\
High & 11 & 8 & 1 & 20 & 4 & 1 & 1 & 6 \\
Total & 28 & 19 & 21 & 68 & 26 & 16 & 20 & 62 \\
\hline
\end{tabular}




\subsection{Early mathematical student skills}

The criteria for early mathematical students skill according to the student's early mathematical skills data are low, medium and high as shown in Table 3.

Table 3. Distribution of early mathematical student skills (EMSS)

\begin{tabular}{cccc}
\hline EMSS & \multicolumn{3}{c}{ Classess } \\
& Experiment & Control & Total \\
\hline Low & 19 & 28 & 47 \\
Medium & 29 & 28 & 57 \\
High & 20 & 6 & 26 \\
Total & 68 & 62 & 130 \\
\hline
\end{tabular}

\subsection{Mathematical reasoning skill}

The following is a description of the results of the pre-test, post-test and improvement of mathematical reasoning skill based on school level, learning and early mathematical skill presented in Table 4 .

Table 4. Description of average mathematical reasoning skills based on early mathematics student skill

\begin{tabular}{|c|c|c|c|c|c|c|c|c|c|c|}
\hline \multirow{3}{*}{ School } & \multirow{3}{*}{ EMSS } & \multirow{3}{*}{$\bar{X} \& \mathrm{SD}$} & \multicolumn{8}{|c|}{ Reasoning skill } \\
\hline & & & & Conventio & & & & RME & & \\
\hline & & & Pre-test & Post-test & $\langle\mathrm{g}\rangle$ & $\mathrm{N}$ & Pre-test & Post-test & $\langle\mathrm{g}\rangle$ & $\mathrm{N}$ \\
\hline \multirow{8}{*}{ Low } & \multirow{2}{*}{ Low } & $\bar{X}$ & 13.14 & 22.20 & 0.10 & \multirow{2}{*}{40} & 14.34 & 25.10 & 0.12 & \multirow{2}{*}{32} \\
\hline & & SD & 5.29 & 6.72 & 0.01 & & 10.06 & 11.33 & 0.01 & \\
\hline & \multirow{2}{*}{ Medium } & $\bar{X}$ & - & - & - & & 52.08 & 63.74 & 0.24 & \multirow{2}{*}{4} \\
\hline & & SD & - & - & - & & - & 6.07 & - & \\
\hline & \multirow{2}{*}{ High } & $\bar{X}$ & - & - & - & \multirow{2}{*}{ - } & - & 86.28 & - & \multirow{2}{*}{6} \\
\hline & & SD & - & - & - & & - & 9.89 & - & \\
\hline & \multirow{2}{*}{ Sub-total } & $\bar{X}$ & 13.14 & 24.20 & 0.13 & \multirow{2}{*}{40} & 66.42 & 75.12 & 0.25 & \multirow{2}{*}{42} \\
\hline & & SD & 5.29 & 6.72 & 0.01 & & 10.055 & 27.29 & 0.19 & \\
\hline \multirow{8}{*}{ Medium } & \multirow{2}{*}{ Low } & $\bar{X}$ & 13.93 & 35.10 & 0.24 & \multirow{2}{*}{30} & 28.36 & 38.49 & 0.14 & \multirow{2}{*}{30} \\
\hline & & SD & 8.49 & 10.56 & 0.02 & & 12.66 & 15.99 & 0.03 & \\
\hline & \multirow{2}{*}{ Medium } & $\bar{X}$ & - & 57.63 & - & \multirow{2}{*}{2} & 61.46 & 67.37 & 0.15 & \multirow{2}{*}{5} \\
\hline & & SD & - & .00000 & - & & - & 6.40 & - & \\
\hline & \multirow{2}{*}{ High } & $\bar{X}$ & - & - & - & \multirow[b]{2}{*}{ - } & - & 84.18 & - & \\
\hline & & SD & - & - & - & & - & 4.89 & - & 3 \\
\hline & & $\bar{X}$ & 13.14 & 46.36 & 0.38 & & 89.82 & 90.04 & 0.02 & \\
\hline & Sub-total & SD & 8.49 & 10.56 & 0.02 & 32 & 12.66 & 27.28 & 0.16 & 38 \\
\hline & & $\bar{X}$ & 13.33 & 27.63 & 0.12 & & 17.34 & 31.62 & 0.21 & \\
\hline & Low & SD & 9.59 & 13.79 & 0.04 & 41 & 8.24 & 11.34 & 0.03 & 32 \\
\hline & & $\bar{X}$ & & 65.14 & 0.22 & & - & 67.13 & - & \\
\hline & Medium & SD & - & 5.63 & - & 12 & - & 7.93 & - & 9 \\
\hline Hign & & $\bar{X}$ & - & 80.00 & - & & - & 89.08 & - & \\
\hline & High & SD & - & 0.0000 & - & 2 & - & 7.72 & - & 9 \\
\hline & & $\bar{X}$ & 13.32 & 57.59 & 0.51 & & 72.54 & 87.85 & 0.55 & $50->$ \\
\hline & Suv-total & SD & 9.59 & 19.42 & 0.10 & 3 & 8.23 & 26.98 & 0.20 & 30 \\
\hline & & $\bar{X}$ & 44.40 & 87.95 & 0.78 & & 56.02 & 95.21 & 0.89 & \\
\hline & Low & SD & 18.08 & 31.07 & 0.15 & 121 & 30.95 & 38.67 & 0.11 & 92 \\
\hline & & $\bar{X}$ & - & 12.77 & - & & 13.54 & 18.25 & 0.05 & \\
\hline Oyerall & Medium & SD & - & 5.63 & - & 14 & - & 20.39 & - & 18 \\
\hline overail & Hiob & $\bar{X}$ & - & 80.00 & - & 2 & - & 259.54 & - & 18 \\
\hline & ПIIII & SD & - & 0.0000 & - & 2 & - & 22.49 & - & 10 \\
\hline & Total & $\bar{X}$ & 44.40 & 60.23 & 0.28 & & 69.56 & 69.63 & 0.002 & \\
\hline & Iotal & SD & 18.08 & 36.71 & 0.22 & & 30.95 & 81.55 & 0.73 & \\
\hline
\end{tabular}

Table 4 shows the description of the average value of pre-test, post-test and improvement in mathematical reasoning skill.

A. Pre-test mathematical reasoning skill

Based on the results of the Pre-test total of mathematical reasoning skill, RME is better than conventional learning, which shows that the mathematical reasoning skill of students with RME is better than the mathematical reasoning skill of students with conventional learning at low, medium and high school level students. However, in both learning, the skill of students in the low category is only in the class taught by conventional learning. 
B. Post mathematical reasoning skill test

Based on the results of the post-test total of students 'mathematical reasoning skills as overall and students' early mathematical skills, it showed that the skills of students 'mathematical reasoning with RME is better than students' mathematical reasoning skills with conventional learning. However, in both learning, students' skills are still in the medium category.

C. Increased mathematical reasoning skill

Based on the total results of the increase in students 'mathematical reasoning skills as overall and the students' early mathematical skills, it shows that the increase in students 'mathematical reasoning skill with RME is better than increased students' mathematical reasoning skill with conventional learning. In both learning, the increased skill of students in both learning is still in the medium category.

\section{Hypothesis testing 1 research into mathematical reasoning skill \\ Hypothesis test 1.a.1}

The hypothesis tested is based on the following pre-test data.

$\mathrm{H}_{0}$ : There is no difference in students' mathematical reasoning skills between those who obtain RME and conventional learning $(\mathrm{CL})$.

$\mathrm{H}_{1}$ : There is a difference in students' mathematical reasoning skills between those who obtain RME and conventional learning (CL).

Test criteria used are if the value of sig. greater than 0.05 , then the null hypothesis (H0) is accepted. The results of normality and homogeneity tests are presented in Table 5 and Table 6.

Table 5. The normality test on mathematical reasoning skill pre-test based on learning

\begin{tabular}{ccccc}
\hline Learning & Statistic & Df & Sig & Ho \\
\hline RME & $35.029^{\mathrm{b}}$ & 30 & .242 & Accepted \\
Conventional & $14.645^{\mathrm{a}}$ & 32 & .996 & Accepted \\
\hline
\end{tabular}

Table 6 . The homogeneity variance test of mathematical reasoning skill pre-test based on learning

\begin{tabular}{cccccc}
\hline & Levene statistic & df1 & df2 & Sig. & Interpretation \\
\hline Pre-test of reasoning & 3.870 & 128 & 123 & .051 & There is no difference \\
\hline
\end{tabular}

Table 5 and Table 6 show that the test is normally distributed and the data variance is homogeneous. Then, the T-test is done with the testing criteria if the sig value. is smaller than 0.05 , then the null hypothesis is rejected. The results of the pre-test T-test of reasoning skill based on learning are presented in Table 7.

Table 7 shows that the results of the T-test pre test the Skill of mathematical reasoning based on learning. Since the value of sig. less than 0.05 , the null hypothesis is rejected. It means that there are significant differences in mathematical reasoning skills based on learning. The pre-test average value of students 'mathematical reasoning skill taught by RME learning is higher at 15.7124 compared to pre tests of students' reasoning skill taught conventionally that was 18.0904 .

Table 7. The pre-test test on mathematical reasoning skill based on learning

\begin{tabular}{ccc}
\hline & sig. (2-tiled) & Ho \\
\hline Pre test of reasoning & 0.003 & Rejected \\
\hline
\end{tabular}

\section{Hypothesis test 1.a.2}

The hypothesis is tested based on post-test data:

$\mathrm{H}_{0}$ : There is no difference in students' mathematical reasoning skills between those who get RME and conventional

$\mathrm{H}_{1}$ : There are differences in students' mathematical reasoning skills between those who get RME and conventional

Table 8 and Table 9 show that the test results are normally distributed and the data is homogeneous variance. Then, the T-test is done with the test criteria is if the sig value is less than 0.05 , then the null hypothesis is rejected. The results of the variance homogeneity test of mathematical reasoning skill post-test based on learning are shown in Table 9. The results of post-test T-test calculation of reasoning skill based on RME and conventional are presented in Table 10.

Table 10 shows that the results of the T-test on mathematical reasoning skill post-test based on learning. Since the value of sig. smaller than 0.05 , the null hypothesis is rejected. It means that there are 
significant differences in students' mathematical reasoning skill based on learning. The average value of the post-test of mathematical reasoning skill of students taught with RME learning was higher at 37.8502 compared to the pre-test of reasoning skill of students who were taught with conventional namely 54.6494 .

Table 8. The normality test of mathematical reasoning skill post-test based on learning

\begin{tabular}{ccccc}
\hline Learning & Statistic & df & Sig & Ho \\
\hline RME & $32.588^{\mathrm{b}}$ & 44 & .898 & Accepted \\
Conventional & $22.645^{\mathrm{a}}$ & 40 & .988 & Accepted \\
\hline
\end{tabular}

Table 9. The homogeneity variance test of mathematical reasoning skill post-test based on learning

\begin{tabular}{cccccc}
\hline & Levene statistic & df1 & df2 & Sig. & Ho \\
\hline Post test of reasoning & 0.354 & 1 & 128 & .533 & Accepted \\
\hline
\end{tabular}

Table 10. T-test post mathematical reasoning skill test based on learning

\begin{tabular}{ccccc}
\hline & T & Df & sig. (2-tailed) & Ho \\
\hline Post reasoning tests & 0.354 & 128 & 0.000 & Rejected \\
\hline
\end{tabular}

\section{Hypothesis test 1.b.1.}

The hypothesis is tested based on pre test data:

$\mathrm{H}_{0}$ : There is no difference in students' mathematical reasoning skills based on EMSS using RME and CL. $\mathrm{H}_{1}$ : There are differences in students' mathematical reasoning skills based on EMSS using RME and CL.

Table 11 and Table 12 show tests of normality and homogeneity that have been carried out. It can be stated that the Pre-test data of mathematical reasoning skill based on the early mathematical skill of students has normal distribution and homogeneous variance. After doing normality and homogeneity tests, then to see if there are differences in pre tests of mathematical reasoning skill based on early mathematical student skills, One-Way Anova test was performed. Test criteria is if the value of sig. smaller than 0.05 , the null hypothesis is rejected. The One-Way Anova test results of mathematical reasoning skills based on early mathematical student skills are presented in Table 13.

Table 11. The normality test of reasoning skill pre-test based on early mathematical student skills (EMSS)

\begin{tabular}{ccccc}
\hline EMSS & Statistic & df & Sig. & Interpretation \\
\hline Low & .983 & 51 & .374 & Accepted \\
Medium & .873 & 1 & .100 & Accepted \\
\hline
\end{tabular}

Table 12. The homogeneity variance test of mathematical reasoning skill pre-test based on early mathematical student skills (EMSS)

\begin{tabular}{cccccc}
\hline & Statistic & df1 & df2 & Sig. & Ho \\
\hline Pre-test of reasoning & 1.233 & 1 & 128 & .269 & Accepted \\
\hline
\end{tabular}

Table 13. The one-way anova test of mathematical reasoning skill pre-test based on early mathematical student skills (EMSS)

\begin{tabular}{ccccc}
\hline & df & F & Sig. & Ho \\
\hline Pre-test & 1 & 21.288 & 0.000 & Rejected \\
\hline
\end{tabular}

Table 13 shows that the One-Way Anova test results on the pre test of mathematical reasoning skill based on students' early mathematical skills, because the sig value is smaller than 0.05 . Thus, the null hypothesis is rejected. It means that there are significant differences in mathematical reasoning skills based on EMSS. The average value of reasoning skill based on EMSS for RME is 31.6250 (low EMSS), 67.1389 (medium EMSS) and 89.0789 (high EMSS) and for CL is 27.6331 (low EMSS), 65.1409 (medium EMSS) and 80.0000 (high EMSS). After calculating the One-Way ANOVA test, a difference in the pre-test of mathematical reasoning skill based on EMSS is performed, the results of which are presented in Table 14.

Table 14 shows that the test results of the pre-test difference in mathematical reasoning skill based on students' early mathematical student skills for groups of low to moderate and low to high, because of the sig. smaller than 0.05 , then differ significantly. Meanwhile, the high group to moderate do not differ significantly because the value of sig. greater than 0.05 . 
Table 14. Pre-test difference test mathematical reasoning skill based on the early mathematical student skills EMSS

\begin{tabular}{ccccc}
\hline \multicolumn{5}{c}{ Multiple comparisons } \\
(I) Group & Dependent variable: Pre-test score Tukey HSD & \\
\hline Low & (J) Group & Mean difference (I-J) & Std. Error & Sig. \\
& Medium & $-47.9258^{*}$ & 3.60793 & .000 \\
\multirow{2}{*}{ Medium } & High & $-70.1667^{*}$ & 3.78734 & .000 \\
& Low & $47.9258^{*}$ & 3.60793 & .000 \\
& High & $-22.2409^{*}$ & 5.02091 & .000 \\
& Low & $70.1667^{*}$ & 3.78734 & .000 \\
& Medium & $22.2409^{*}$ & 5.02091 & .000 \\
\hline
\end{tabular}

Based on observed means, the error term is mean square (Error) $=119.413$.

$*$ The mean difference is significant at the 0.05 level.

\section{Hypothesis testing 1.b.2.}

The hypothesis is tested based on post-test data:

$\mathrm{H}_{0}$ : There is no difference in students' mathematical reasoning skills based on early mathematical student skills using RME and conventional.

$\mathrm{H}_{1}$ : There are differences in students' mathematical reasoning skills based on early mathematical student skills using RME and conventional.

Table 15 shows that the test results are normally distributed and Table 16 shows the results of the Kurskal-Walls on the post-test mathematical reasoning skill that is based on early mathematical student skills, because the sig. is smaller than 0.05 . Thus, the null hypothesis is rejected. It means that there are significant differences in students' mathematical reasoning skills. After conducting the Kurskal-Walls test, it is continued with the Mann-Whitney test to compare the reasoning skill of low group students against medium groups and low groups against high groups and T-tests of moderate group students with high group students, the results of which are presented in Table 17.

Table 17 shows that the results of the post-test difference test (Two ways Anova Test) of mathematical reasoning skill based on the early mathematical student skills are low, medium and high. It shows that sig. smaller than 0.05 . This means that the post-test of mathematical reasoning skill based on the early mathematical student skills of low group to moderate groups, low groups to high groups and moderate groups to high groups is significantly different.

Table 15. The normality test of mathematical reasoning skill post-test based on early mathematical student skills (EMSS)

\begin{tabular}{ccccc}
\hline SES & Statistic & df & Sig. & Ho \\
\hline Low & .155 & 85 & .000 & Rejected \\
Medium & .140 & 31 & .123 & Accepted \\
High & .199 & 14 & .137 & Accepted \\
\hline
\end{tabular}

Table 16. The kruskal-wallis test of mathematical reasoning skill post-test based on early mathematical student skills (EMSS)

\begin{tabular}{ccccc}
\hline Post-test & Chi-square & df & Sig. & Ho. \\
\hline & 21.789 & 2 & 0.000 & Rejected \\
\hline
\end{tabular}

Table 17. The test difference of mathematical reasoning skill post-test based on students' early mathematical

\begin{tabular}{ccccc}
\multicolumn{5}{c}{ Skills (EMSS) } \\
\hline \multicolumn{5}{c}{ Multiple comparisons } \\
(I) SES & Dependent variable: Post-test Tukey HSD score \\
\hline Low & (J) SES & Mean difference (I-J) & Std. Error & Sig. \\
& Medium & $-38.5182^{*}$ & 2.46591 & .000 \\
Medium & High & $-55.2282^{*}$ & 3.38987 & .000 \\
& Low & $38.5182^{*}$ & 2.46591 & .000 \\
& High & $-16.7100^{*}$ & 3.78443 & .000 \\
High & Low & $55.2282^{*}$ & 3.38987 & .000 \\
\hline
\end{tabular}

\subsection{Mathematical communication skills}

The following is a description of the results of pre-test, post-test and improvement of mathematical communication skills (Gain) based on school level, learning and early mathematical student skills. The details are presented in Table 18. 
Table 18. Description of average mathematical communication skills based on learning and early mathematical student skills (EMSS)

\begin{tabular}{|c|c|c|c|c|c|c|c|c|c|c|}
\hline \multirow{3}{*}{ School } & \multirow{3}{*}{ SES } & \multirow{3}{*}{$\bar{X} \& \mathrm{SD}$} & \multicolumn{8}{|c|}{ Communication skills } \\
\hline & & & \multicolumn{4}{|c|}{ CL } & \multicolumn{4}{|c|}{ RME } \\
\hline & & & Pre & Pos & $\langle\mathrm{g}\rangle$ & $\mathrm{N}$ & Pre & Pos & $\langle\mathrm{g}\rangle$ & $\mathrm{N}$ \\
\hline \multirow{8}{*}{ Low } & \multirow{2}{*}{ Low } & $\bar{X}$ & 39.28 & 47.66 & 0.13 & \multirow{2}{*}{23} & 40.36 & 50.40 & 0.16 & \multirow{2}{*}{12} \\
\hline & & SD & 6.69 & 10.33 & 0.03 & & 5.89 & 7.73 & 0.01 & \\
\hline & \multirow{2}{*}{ Medium } & $\bar{X}$ & 61.07 & 62.85 & 0.04 & \multirow{2}{*}{11} & 62.25 & 64.50 & 0.05 & \multirow{2}{*}{17} \\
\hline & & SD & 5.69 & 6.55 & 0.009 & & 5.50 & 6.92 & 0.01 & \\
\hline & \multirow{2}{*}{ High } & $\bar{X}$ & 76.40 & 79.00 & 0.11 & \multirow{2}{*}{6} & 79.00 & 80.67 & 0.07 & \multirow{2}{*}{13} \\
\hline & & SD & 0 & 3.13 & 0.03 & & 0.57 & 5.63 & 0.05 & \\
\hline & \multirow{2}{*}{ Sub-total } & $\bar{X}$ & 54.2 & 54.55 & 0.007 & \multirow{2}{*}{40} & 61.33 & 62.57 & 0.03 & \multirow{2}{*}{42} \\
\hline & & SD & 11.09 & 18.10 & 0.07 & & 11.03 & 19.01 & 0.08 & \\
\hline \multirow{8}{*}{ Medium } & \multirow{2}{*}{ Low } & $\bar{X}$ & 41.00 & 42.33 & 0.02 & \multirow{2}{*}{10} & 52.00 & 53.00 & 0.02 & \multirow{2}{*}{2} \\
\hline & & SD & 6.92 & 7.57 & 0.006 & & 0 & 0 & 0 & \\
\hline & \multirow{2}{*}{ Medium } & $\bar{X}$ & 64.00 & 64.18 & 0.005 & \multirow{2}{*}{19} & 64.33 & 68.72 & 0.12 & \multirow{2}{*}{21} \\
\hline & & SD & 6.00 & 7.49 & 0.01 & & 6.03 & 6.44 & 0.004 & \\
\hline & High & $\bar{X}$ & 76.00 & 79.00 & 0.12 & & 81.71 & 83.33 & 0.08 & \\
\hline & High & SD & 0 & 1.41 & 0.01 & 3 & 4.68 & 5.43 & 0.007 & 16 \\
\hline & Sub-total & $\bar{X}$ & 54.68 & 61.93 & 0.15 & 32 & 72.46 & 72.68 & 0.007 & \\
\hline & Sub-total & SD & 12.18 & 14.14 & 0.02 & 32 & 9.50 & 12.12 & 0.02 & 39 \\
\hline & I ow & $\bar{X}$ & 32.25 & 45.40 & 0.19 & & 42.75 & 50.40 & 0.13 & \\
\hline & Low & SD & 3.64 & 6.48 & 0.02 & 17 & 1.78 & 11.81 & 0.10 & 9 \\
\hline & & $\bar{X}$ & 58.90 & 59.28 & 0.009 & 25 & 64.50 & 66.76 & 0.06 & \\
\hline High & Medium & SD & 3.96 & 4.58 & 0.006 & 25 & 5.79 & 5.91 & 0.001 & 29 \\
\hline High & & $\bar{X}$ & 77.66 & 83.85 & 0.27 & & 80.10 & 87.14 & 0.35 & \\
\hline & High & SD & 0.57 & 3.23 & 0.02 & 10 & 6.13 & 7.28 & 0.01 & 17 \\
\hline & & $\bar{X}$ & 55.61 & 63.23 & 0.17 & & 73.62 & 74.35 & 0.02 & \\
\hline & Sub-total & SD & 12.77 & 14.38 & 0.01 & 52 & 13.85 & 15.53 & 0.01 & 65 \\
\hline & I онш & $\bar{X}$ & 41.69 & 45.25 & 0.06 & 50 & 42.46 & 47.30 & 0.08 & 23 \\
\hline & Low & SD & 6.69 & 8.19 & 0.01 & 50 & 6.95 & 9.00 & 0.02 & 23 \\
\hline & Medium & $\bar{X}$ & 61.44 & 62.00 & 0.01 & 55 & 64.30 & 65.88 & 0.04 & 67 \\
\hline Overoll & Medium & SD & 5.51 & 6.41 & 0.009 & 55 & 6.21 & 6.65 & 0.004 & $6 /$ \\
\hline Overall & & $\bar{X}$ & 77.30 & 82.44 & 0.22 & & 80.11 & 84.31 & 0.21 & \\
\hline & High & SD & 2.40 & 4.03 & 0.01 & 19 & 5.50 & 6.05 & 0.005 & 46 \\
\hline & Total & $\bar{X}$ & 60.33 & 62.04 & 0.04 & 124 & 62.29 & 65.83 & 0.09 & 146 \\
\hline & Iotal & SD & 5.41 & 5.67 & 0.002 & 124 & 6.37 & 7.07 & 0.007 & 140 \\
\hline
\end{tabular}

Table 18 shows a description of the average value of pre-test, post-test and improvement in the skill (gain) of mathematical communication as:

A. Pre-test of mathematical communication skills.

Bassed on the total pre test results of students' overall mathematical communication skills and early mathematical student skills, it shows that the pre test of students 'mathematical communication skills with RME is better than the pre tests of students' mathematical communication skills with conventional. However, in both learning, students' skills are still in the medium category.

B. Post-test of mathematical communication skills.

Based on the total post-test results of students' overall mathematical communication skills and early mathematical student skills, it shows that the post-test students 'mathematical communication skills with RME were better than the students' mathematical communication skill post-test with conventional. However, in both learning, students' skills are still in the medium category.

C. Improving the skill (Gain) of mathematical communication

Based on the total results of an increase in overall students' mathematical communication skills and early mathematical student skills, it shows that increasing students' mathematical communication skills with RME is better than increasing students' conventional mathematical communication skills. However, in both learning, the improvement of students' skills is still a medium category.

\section{Research hypothesis testing on the mathematical communication skills Hypothesis testing 2.a.1}

The hypothesis is tested based on pre-test data, namely: Mathematical communication skills of students who use RME is better than CL in terms of overall students.

$\mathrm{H}_{0:} \mu_{1} \leq \mu_{2}$

$\mathrm{H}_{1:} \mu_{1}>\mu_{2}$

Note: $\mu_{1}=$ Mathematical communication skills using RME

$\mu_{2}=$ Mathematical communication skills using conventional 
Table 19 and Table 20 show that testing is normal and homogeneous. Furthermore, the calculation of T-test for communication skills pre-test that is based on learning is presented in Table 21. Table 21 shows that the results of the Pre-test T-test of mathematical communication skills based on learning, because the value of sig. less than 0.05 . Thus, the null hypothesis is rejected. It means that there are significant differences in mathematical communication skills based on learning. The average value of the pre test of mathematical communication skills of students taught with RME learning was higher at 67.3971 compared to the pre tests of communication skills of students who were taught with conventional at 58.2258.

Table 19. The normality test of mathematical communication skill pre-test based on learning

\begin{tabular}{ccccc}
\hline Learning & Statistic & df & Sig & Ho \\
\hline RME & .075 & 68 & $.200^{*}$ & Accepted \\
CL & .096 & 62 & $.200^{*}$ & Accepted \\
\hline
\end{tabular}

Table 20. The homogeneity variance test of mathematical communication skill pre-test based on learning

\begin{tabular}{cccc}
\hline & Sig. & $\alpha$ & Interpretation \\
\hline Pre test of reasoning & .051 & 0.05 & No difference \\
\hline
\end{tabular}

Table 21. Pre-test t-test of mathematical communication skills based on learning

\begin{tabular}{ccccc}
\hline & $\mathrm{T}$ & $\mathrm{df}$ & sig. (2-tailed) & Ho \\
\hline Pre test of reasoning & 3.771 & 128 & 0.000 & Rejected \\
\hline
\end{tabular}

\section{Hypothesis testing 2.a.2}

The hypothesis was tested based on the post-test, namely: Mathematical communication skills of students who use RME better than CL in terms of overall students.

$\mathrm{H}_{0:} \mu_{1} \leq \mu_{2}$

$\mathrm{H}_{1:} \mu_{1}>\mu_{2}$

Note: $\mu_{1}=$ Mathematical communication skills using RME

$\mu_{2}=$ Mathematical communication skills using conventional

The normality test of mathematical communication skill post-test based on learning as shown in Table 22. Table 23 shows that the Mann-Whitney test results on mathematical communication skills post-test based on learning. Since the sig. less than 0.05 , the null hypothesis is rejected. It means that there are differences in student communication skills based on learning. Based on the data about the average value of mathematical communication skills based on learning and according to the results of the post-test, it is known that there are significant differences. The average post-test score of mathematical communication skills of students who get RME is 69.2090 and the average value of students who get conventional is 55.9516. After conducting the normality test, it is known that the data is not normally distributed for both learning. Then, the Mann-Whitney test was carried out with results as shown in Table 23.

Table 22. The normality test of mathematical communication skill post-test based on learning

\begin{tabular}{ccccc}
\hline Learning & Statistic & df & Sig & $\mathrm{H}_{0}$ \\
\hline RME & .137 & 67 & .005 & Rejected \\
CL & .135 & 62 & .200 & Accepted \\
\hline
\end{tabular}

Table 23. The Mann-Whitney test of mathematical communication skill post-test based on learning

\begin{tabular}{ccccc}
\hline & Wilcoxon & $\mathrm{Z}$ & Aymp sig.n (2-tailed) & Ho \\
\hline Communication test post & 3026.500 & -4.734 & .000 & Rejected \\
\hline
\end{tabular}

\section{Hypothesis testing 2.b.1}

The hypothesis that is tested based on the pre-test is: Mathematical communication skills of students who use RME are better than conventional in terms of students' early mathematical skills.

$\mathrm{H}_{0:} \mu_{1}=\mu_{2}=\mu_{3}$

$\mathrm{H}_{1}$ : There is at least one mathematical communication skill based on a different EMSS

Note : $\mu_{1}=$ Mathematical communication skills of low group students

$\mu_{2}=$ Mathematical communication skills of medium group students

$\mu_{3}=$ Mathematical communication skills of high group students 
Table 24 shows the results of the normality test on mathematical communication skills pre-test that is based on early mathematical student skills. The data are not normally distributed. After that, the Mann-Whitney test is carried out with the results shown in Table 25.

Table 24. The normality test on mathematical communication skills pre-test based on early mathematical

\begin{tabular}{ccccc}
\multicolumn{5}{c}{ student skills (EMSS) } \\
\hline & Statistic & df & Sig. & Ho \\
\hline Low & .244 & 26 & .000 & Rejected \\
Medium & .138 & 76 & .001 & Rejected \\
High & .230 & 28 & .001 & Rejected \\
\hline
\end{tabular}

Table 25. The Mann-Whitney test on mathematical communication skills pre-test based on early mathematical student skills (EMSS)

\begin{tabular}{ccccc}
\hline & Wilcoxon & $\mathrm{Z}$ & Aymp sig. (2-tailed) & Ho \\
\hline Pre test communication & 502.500 & -6.437 & .000 & Rejected \\
\hline
\end{tabular}

Table 25 shows that the results of the Mann-Whitney test on mathematical communication skills posttest are based on early mathematical student skills, because of the sig. less than 0.05 , the null hypothesis is rejected. It means that there are differences in student communication skills based on early mathematical student skills. Based on the data about the average value of mathematical communication skills and mathematical early skill and according to the results of the pre-test, it it is known that there are significant differences. Table 26 shows that the test results of the difference test on mathematical communication skills Pre-test based on students' early mathematical skills are significantly different so that the data are also significantly different.

Table 26. The difference test on mathematical communication skills pre-test based on early mathematical

\begin{tabular}{cccccc}
\multicolumn{8}{c}{ Student skills (EMSS) } \\
\hline \multirow{2}{*}{ Low } & $(\mathrm{J})$ Group & Mean difference (I-J) & Std. Error & Sig. & Interpretation \\
& Medium & $-13.98482^{*}$ & 1.82740 & .000 & There is a difference \\
\multirow{3}{*}{ Medium } & High & $-36.79121^{*}$ & 2.19057 & .000 & There is a difference \\
& Low & $13.98482^{*}$ & 1.82740 & .000 & There is a difference \\
& High & $-22.80639^{*}$ & 1.77810 & .000 & There is a difference \\
& Low & $36.79121^{*}$ & 2.19057 & .000 & There is a difference \\
& Medium & $22.80639^{*}$ & 1.77810 & .000 & There is a difference \\
\hline
\end{tabular}

\section{Submission of hypotheses 2.b.2}

$\mathrm{H}_{0:} \mu_{1}=\mu_{2}=\mu_{3}$

$\mathrm{H}_{1}$ : There is at least one mathematical communication skill based on different early mathematical skills

Note : $\mu_{1}=$ Mathematical communication skills of low group students

$\mu_{2}=$ Mathematical communication skills of medium group students

$\mu_{3}=$ Mathematical communication skills of high group students

Table 27 shows that data are normally distributed. In addition, Table 28 shows that the Mann-Whitney test results on the post-test mathematical communication skills that are based on early mathematical student skills have a sig. smaller than 0.05 . Thus, the null hypothesis is rejected. It means that there are significant differences in mathematical communication skills based on early mathematical student skills. After conducting the Mann-Whitney test, it was followed by the Tukey test to compare the communication skills of low group students with medium group students and low group students with high group students. Then, it proceeds with the T-test to compare medium group students with high group students. The results of which are presented in Table 29.

Table 29 shows the test results of the differences test on mathematical communication skills post-test are based on early mathematical student skills. Since the significance is smaller than 0.05 , it means that there are differences in the data. Thus, the mathematical communication skills tests based on students' early mathematical skills (low, medium and high) differ significantly. 
Table 27. The normality test on mathematical communication skills post-test based on early mathematical student skills (EMSS)

\begin{tabular}{ccccc}
\hline SES & Statistic & df & Sig. & Interpretation \\
\hline Low & .953 & 86 & .191 & Accepted \\
Medium & .922 & 16 & .001 & Rejected \\
High & .898 & 4 & .001 & Rejected \\
\hline
\end{tabular}

Table 28. The Mann-Whitney test on mathematical communication skills post-test based on early mathematical student skills (EMSS)

\begin{tabular}{ccccc}
\hline & Wilcoxon & $\mathrm{Z}$ & Aymp sig. (2-tailed) & Ho \\
\hline Communication test post & 780.000 & -8.173 & .000 & Rejected \\
\hline
\end{tabular}

Table 29. The difference test on mathematical communication skills post-test based on students' early mathematical skills (EMSS)

\begin{tabular}{cccccc}
\hline (I) Group & $(\mathrm{J})$ Group & Mean difference $(\mathrm{I}-\mathrm{J})$ & Std. Error & Sig. & Interpretation \\
\hline \multirow{2}{*}{ Low } & Medium & $-22.03241^{*}$ & 1.38079 & .000 & There is a difference \\
& High & $-37.40263^{*}$ & 1.50202 & .000 & There is a difference \\
Medium & Low & $22.03241^{*}$ & 1.38079 & .000 & There is a difference \\
& High & $-15.37022^{*}$ & 1.40212 & .000 & There is a difference \\
& High & $37.40263^{*}$ & 1.50202 & .000 & There is a difference \\
& Medium & $15.37022^{*}$ & 1.40212 & .000 & There is a difference \\
\hline
\end{tabular}

The results of descriptive analysis and statistical tests show that there are significant differences in the improvement of mathematical reasoning skills with learning with RME when compared with conventional learning. Increased mathematical reasoning skills occur at each level of the school because the acquisition of mathematical problems oriented to everyday local life. The average rural student in Maluku, especially in Central Maluku, still uses a pattern from the ancestors in the form of the Nanaku system or predictions of possible answers. However, with RME based on local culture, the teacher designs learning to instill mathematical concepts in stimulating mathematical reasoning and communication skills in everyday contexts. The results show that RME can improve mathematical reasoning and communication skills of junior high school students because the local cultural environment is very influential on improving students' mathematical reasoning. Students no longer compare and imagine mathematical conditions that have never been seen or felt, but can apply according to the local context that occurs. The results of this study are in line with Piaget's learning theory which states that the basic principles of a person's knowledge will change and adapt to the surrounding reality [29].

The results of the study provide information that there are differences in increasing mathematical reasoning skills based on the learning approach that is RME and conventional. Improved mathematical reasoning and communication skills occur because the RME approach starts from the local context of an area. The process of developing concepts and ideas starts from real life and ultimately reflects the results obtained in mathematics back to the real world [30]. Learning starts from giving contextual problems so that in cultural life that facilitates mathematical understanding, students are given the opportunity to solve these problems in their own way according to the schema they have in mind by paying attention to the principles and characteristics of RME.

Through the RME principle, learning is focused on students' skill to rediscover. It is begun with problem solving with the help of student activity sheets designed with attention to the character and culture of the Maluku region. This is in line with Vygotsky's theory which introduces the term scaffolding, namely learning assistance provided by teachers [31]. For example, assistance in the form of instructions or guidelines in the form of worksheets that are designed by the teacher. This is a stimulus in the form of questions in local life that are constructive to stimulate students' mathematical communication. The results of the Thai study provide information that communicative learning based on local wisdom can improve critical skills, creativity and student learning outcomes and the formation of student characteristics in solving everyday problems [32].

Mathematics learning in the form of RME which is local wisdom, is expected to stimulate students' thinking in the context of analysis. So that supports the development of mathematical reasoning and communication skills of students. Things included in the indicators that is measured in mathematical reasoning skills are identifying relevant and irrelevant data, connecting the interconnection of two or more concepts, analyzing problems and solving problems.

The observations at every meeting in the RME class inform that the learning process has taken place in accordance with the principles, character and steps of the RME such as student activities in responding to class discussions and student activeness in responding to learning from the teacher. It happens because RME 
stages facilitate the improvement of mathematical skills and mathematical communication. All of this lies on the teacher for how to design good learning so that students' mathematical results can improve. By using RME, students are more active in class in communicating to solve mathematichal problem when compared to students who study conventionally in which the teacher as a center for mathematical learning and students' mathematical emotional is individual.

\section{CONCLUSION}

Realistic mathematics education (RME) has a significant influence on students' mathematical reasoning and communication skills at each level of the school for the rural context. Thus, RME is recommended in improving students' mathematical reasoning and communication skills in the island-based rural context. There are some suggestions: 1) RME to improve the skill to think critically and mathematically creative, students' character should be used as a learning approach by prioritizing cultural aspects that can be used by teachers in schools, especially for low and medium level schools and the selection of adjusted material in the context of RME. In implementing RME, teachers should prepare learning tools and be guided by the applicable curriculum; 2) In applying RME, the teacher should prepare students with the mastery of prerequisite material to improve early mathematical student skills so that the learning outcomes obtained are better and will increase their mathematical creative and critical thinking skills; 3) The implementation of realistic mathematics education (RME) should prioritize students' activeness because students construct their own mathematical material through learning tools prepared by the teacher according to the real-world context and students' daily lives. Teacher assistance is only necessary to direct students to understand a material or answer questions as well as increase students' criticism and creativity.

\section{REFERENCES}

[1] T. Wasahua, Y. Koesmaryono, and I. Sailah, "Evaluation Policy on Assistance Program Bidikmisi Higher Education in Private Kopertis Region XII," J. Educ. e-Learning Res, vol. 5, no. 1, pp. 1-7, 2018, doi: 10.20448/journal.509.2018.51.1.7.

[2] S. Masino and M. Niño-Zarazúa, "What works to improve the quality of student learning in developing countries?" Int. J. Educ. Dev, vol. 48, pp. 53-65, 2016, doi: 10.1016/j.ijedudev.2015.11.012.

[3] T. Correa and I. Pavez, "Digital Inclusion in Rural Areas: A Qualitative Exploration of Challenges Faced by People From Isolated Communities," J. Comput. Commun, vol. 21, no. 3, pp. 247-263, 2016, doi: 10.1111/jcc4.12154.

[4] G. Knijnik and F. Wanderer, "Mathematics Education in Brazilian Rural Areas: An analysis of the Escola Ativa public policy and the Landless Movement Pedagogy," Open Rev. Educ. Res, vol. 2, no. 1, pp. 143-154, 2015, doi: 10.1080/23265507.2015.1052009.

[5] C. Walkington, D. Woods, M. J. Nathan, G. Chelule, and M. Wang, "Does restricting hand gestures impair mathematical reasoning?" Learn. Instr, vol. 64, Dec. 2019, doi: 10.1016/j.learninstruc.2019.101225.

[6] L. Sumpter and M. Hedefalk, "Preschool children's collective mathematical reasoning during free outdoor play," $J$. Math. Behav., vol. 39, pp. 1-10, 2015, doi: 10.1016/j.jmathb.2015.03.006.

[7] A. Teledahl, "How young students communicate their mathematical problem solving in writing," Int. J. Math. Educ. Sci. Technol, vol. 48, no. 4, pp. 555-572, 2017, doi: 10.1080/0020739X.2016.1256447.

[8] D. Otoo, W. A. Iddrisu, J. A. Kessie, and E. Larbi, "Structural Model of Students' Interest and Self-Motivation to Learning Mathematics," Educ. Res. Int, vol. 2018, 2018, doi: 10.1155/2018/9417109.

[9] B. C. Gunhan, "A case study on the investigation of reasoning skills in geometry," South African J. Educ. vol. 34, no. 2, pp. 1-19, 2014, doi: 10.15700/201412071156.

[10] J. S. Woolley, et al., "Undergraduate students demonstrate common false scientific reasoning strategies," Think. Ski. Creat, vol. 27, no. December 2017, pp. 101-113, 2018, doi: 10.1016/j.tsc.2017.12.004.

[11] P. Yuanita, H. Zulnaidi, and E. Zakaria, "The effectiveness of Realistic Mathematics Education approach : The role of mathematical representation as mediator between mathematical belief and problem solving," PLoS One, vol. 12, no. 9, pp. 1-20, 2018, doi: 10.1371/journal.pone.0204847.

[12] M. van den Heuvel-Panhuizen, "The didactical use of models in realistic," Educ. Stud. Math, vol. 54, pp. 9-35, 2003.

[13] S. Sumirattana, A. Makanong, and S. Thipkong, "Using realistic mathematics education and the DAPIC problemsolving process to enhance secondary school students' mathematical literacy," Kasetsart J. Soc. Sci, vol. 38, no. 3, pp. 307-315, 2017, doi: 10.1016/j.kjss.2016.06.001.

[14] R. K. Sembiring, S. Hadi, and M. Dolk, "Reforming mathematics learning in Indonesian classrooms through RME," ZDM - Int. J. Math. Educ, vol. 40, no. 6, pp. 927-939, 2008, doi: 10.1007/s11858-008-0125-9.

[15] K. Gravemeijer and J. Terwel, "Hans Freudenthal: A mathematician on didactics and curriculum theory," J. Curric. Stud., vol. 32, no. 6, pp. 777-796, 2000, doi: 10.1080/00220270050167170.

[16] H. C. Hill, et al., "Mathematical knowledge for teaching and the mathematical quality of instruction: An exploratory study," Cogn. Instr., vol. 26, no. 4, pp. 430-511, 2008, doi: 10.1080/07370000802177235.

[17] P. Serdyukov, "Innovation in education: what works, what doesn't, and what to do about it?" J. Res. Innov. Teach. Learn., vol. 10, no. 1, pp. 4-33, 2017, doi: 10.1108/jrit-10-2016-0007.

[18] D. I. Craig, "Brain-compatible learning: principles and applications in athletic training," J. Athl. Train, vol. 38, no. 4, pp. 342-349, 2003. 
[19] G. Bento and G. Dias, "The importance of outdoor play for young children's healthy development," Porto Biomed. J., vol. 2, no. 5, pp. 157-160, 2017, doi: 10.1016/j.pbj.2017.03.003.

[20] M. De Vita, L. Verschaffel, and J. Elen, "The power of interactive whiteboards for secondary mathematics teaching: Two case studies," J. Educ. Technol. Syst, vol. 47, no. 1, pp. 50-78, 2018, doi: 10.1177/0047239518767112.

[21] K. C. Margot and T. Kettler, "Teachers' perception of STEM integration and education: a systematic literature review," Int. J. STEM Educ, vol. 6, no. 1, 2019, doi: 10.1186/s40594-018-0151-2.

[22] A. Bray and B. Tangney, "Enhancing student engagement through the affordances of mobile technology: a 21st century learning perspective on Realistic Mathematics Education,” Math. Educ. Res. J, vol. 28, no. 1, pp. 173-197, 2016, doi: 10.1007/s13394-015-0158-7.

[23] M. Tamur, D. Juandi, and A. M. G. Adem, "Realistic Mathematics Education in Indonesia and Recommendations for Future Implementation: A Meta-Analysis Study,” J. Teor. dan Apl. Mat, vol. 4, no. 1, pp. 17-27, 2020, doi: 10.31764 jtam.v4i1.1786.

[24] M. Salam, N. Ibrahim, and M. Sukardjo, "Effects of instructional models and spatial intelligence on the mathematics learning outcomes after controlling for students' initial competency," Int. J. Instr, vol. 12, no. 3, pp. 699-716, 2019, doi: 10.29333/iji.2019.12342a.

[25] D. P. Zwart, J. E. H. Van Luit, O. Noroozi, and S. L. Goei, "The effects of digital learning material on students' mathematics learning in vocational education," Cogent Educ, vol. 4, no. 1, pp. 1-10, 2017, doi: 10.1080/2331186X.2017.1313581.

[26] T. Laurens, F. A. Batlolona, J. R. Batlolona, and M. Leasa, "How does realistic mathematics education (RME) improve students' mathematics cognitive achievement?" Eurasia J. Math. Sci. Technol. Educ, vol. 14, no. 2, 2018, doi: $10.12973 /$ ejmste/76959.

[27] A. L. Palinussa, "Students' critical mathematical thinking skills and character: Experiments for junior high school students through realistic mathematics education culture-based," J.M.E, vol. 4, no. 1, pp. 75-94, 2013.

[28] L. L. Figueroa, S. Lim, and J. Lee, "Investigating the relationship between school facilities and academic achievements through geographically weighted regression,” Ann. GIS, vol. 22, no. 4, pp. 273-285, 2016, doi: 10.1080/19475683.2016.1231717.

[29] B. Hanfstingl, G. Benke, and Y. Zhang, "Comparing variation theory with Piaget's theory of cognitive development: more similarities than differences?" Educ. Action Res, vol. 27, no. 4, pp. 511-526, 2019, doi: 10.1080/09650792.2018.1564687.

[30] K. L. Kritzer and C. M. Pagliaro, "An intervention for early mathematical success: Outcomes from the hybrid version of the building math readiness parents as partners (MRPP) project," J. Deaf Stud. Deaf Educ, vol. 18, no. 1, pp. 30-46, 2013, doi: 10.1093/deafed/ens033.

[31] A. Shvarts and A. Bakker, "The early history of the scaffolding metaphor: Bernstein, Luria, Vygotsky, and before," Mind, Cult. Act, vol. 26, no. 1, pp. 4-23, 2019, doi: 10.1080/10749039.2019.1574306.

[32] S. Santiprasitkul, K. Sithivong, and O. Polnueangma, "The first year nursing students' achievement and critical thinking in local wisdom course using problem based learning process," Wirel. Pers. Commun, vol. 69, no. 3, pp. 1077-1085, 2013, doi: 10.1007/s11277-013-1067-2. 